\title{
Water quality of the surfaces waters of the Strazym Lake
}

\section{Ocena jakości wód powierzchniowych jeziora Strażym}

\author{
Piotr Daniszewski \\ Katedra Chemii i Ochrony Środowiska Wodnego \\ Wydział Biologii \\ Uniwersytet Szczeciński \\ ul. Felczaka 3C, 71-412 Szczecin, Poland \\ E-mail address: daniszewski@univ.szczecin.pl
}

\begin{abstract}
To estimate differentiation of water chemistry in reservoirs of Strażym Lake, in time of 2008. In arbitrary appointed times 19 physical and chemical indicators of water quality were determined to evaluate general status and water condition (temperature, $\mathrm{pH}$, concentration of dissolved oxygen and saturation by $\mathrm{O}_{2}$, solid residue, residue after ignition), trophy (concentrations of $\mathrm{NO}_{3}^{-}, \mathrm{NO}_{2}^{-}, \mathrm{NH}_{4}^{+}$, $\mathrm{PO}_{4}{ }^{3-}$ dissolved., $\mathrm{P}_{\text {tot. }}$ ), and mineralization (specyfic electrolytic conductivity, total hardness and separately concentrations of $\mathrm{Ca}^{2+}, \mathrm{Mg}^{2+}$ and $\mathrm{Cl}^{-}, \mathrm{SO}_{4}^{2-}$, total concentrations of $\mathrm{Fe}$ and $\mathrm{Mn}$ ).
\end{abstract}

Keywords:

Lakes; natural water quality; phosphorus; nitrogen; Strazym Lake

\section{STRESZCZENIE}

Celem niniejszej pracy było prześledzenie w okresie od lipca do września 2009 roku poziomu oraz dynamiki zmian w wodach jeziora Strażym sezonowych parametrów ogólnych, zasobności wód w substancje biogenne a także poziomu wskaźników mineralizacji. W pracy oznaczano wskaźniki ogólne wody: temperaturę, $\mathrm{pH}$, Eh, alkaliczność ogólną wody, stężenie $\mathrm{O}_{\text {2rozp. }}$ ChZT-Mn, suchą pozostałość i pozostałość po prażeniu. Spośród wskaźników charakteryzujących trofię oznaczono: stężenia $\mathrm{NO}_{3}^{-}, \mathrm{NO}_{2}{ }^{-}, \mathrm{NH}_{4}{ }^{+}, \mathrm{PO}_{4}{ }^{3-}$ roz.,, $\mathrm{P}_{\text {og }}$ oraz wskaźniki charakteryzujące mineralizację wód: twardość ogólną, stężenie $\mathrm{Ca}^{2+}, \mathrm{Mg}^{2+}, \mathrm{Cl}^{-}, \mathrm{SO}_{4}{ }^{2-}$, ogólne stężenie $\mathrm{Fe}$ i Mn.

\section{Stowa kluczowe:}

jeziora, jakość wód, fosfor, azot, jezioro Strażym 


\section{WPROWADZENIE}

Zmiany jakie zachodzą $\mathrm{w}$ środowisku naturalnym są nieodłącznie związane $\mathrm{z}$ rozwojem cywilizacyjnym $[5,7-9,22,23]$. W środowisku wodnym objawia się to wzrostem zanieczyszczenia m.in. związkami biogennymi, które mają istotny wpływ na proces eutrofizacji zbiorników wodnych $[1,21,22]$. Efektem tego są zakłócenia o różnym natężeniu w równowadze ekologicznej danego akwenu [1, 5-7, 9, 21, 22]. Szczególnie wrażliwe na zanieczyszczenia związkami biogennymi są jeziora $[22,23]$. Prowadzone badania w różnych ośrodkach naukowych nad rolą, zawartością a także przemianami związków biogenicznych w środowisku wodnym wykazały, że podstawowym czynnikiem pokarmowym, kontrolującym rozwój mikroorganizmów planktonowych jest przede wszystkim zawartość związków fosforu $[1,5-8,14,16,20]$.

Celem niniejszej pracy było prześledzenie w okresie od lipca do września 2009 roku poziomu oraz dynamiki zmian w wodach jeziora Strażym sezonowych parametrów ogólnych, zasobności wód w substancje biogenne a także poziomu wskaźników mineralizacji.

\section{CZECŚĆ DOŚWIADCZALNA}

Badania przeprowadzono na jeziorze Strażym. Jezioro Strażym położone jest w województwie kujawsko - pomorskim, w powiecie brodnickim, w gminie Zbiczno [2-4].

Jest to jezioro polodowcowe, przepływowe (rzeka Skarlanka) jezioro rynnowe, otoczone $\mathrm{w}$ przeważającej części lasami iglastymi, leżące pomiędzy jeziorami Zbiczno, a Bachotkiem [2-4].

Dane morfometryczne jeziora:

- Powierzchnia zwierciadła wody 75,0 ha,

- Zwierciadło wody położone jest na wysokości 71,3 m n.p.m.,

- Średnia głębokość jeziora wynosi 3,5 m,

- Głębokość maksymalna 9,0 m,

- Objętość wód w jeziorze według różnych źródeł wynosi 2566,0 tys. m³ [2-4]

Rozmieszczenie punktów badawczych na jeziorze Strażym przedstawiono na schemacie nr 1.

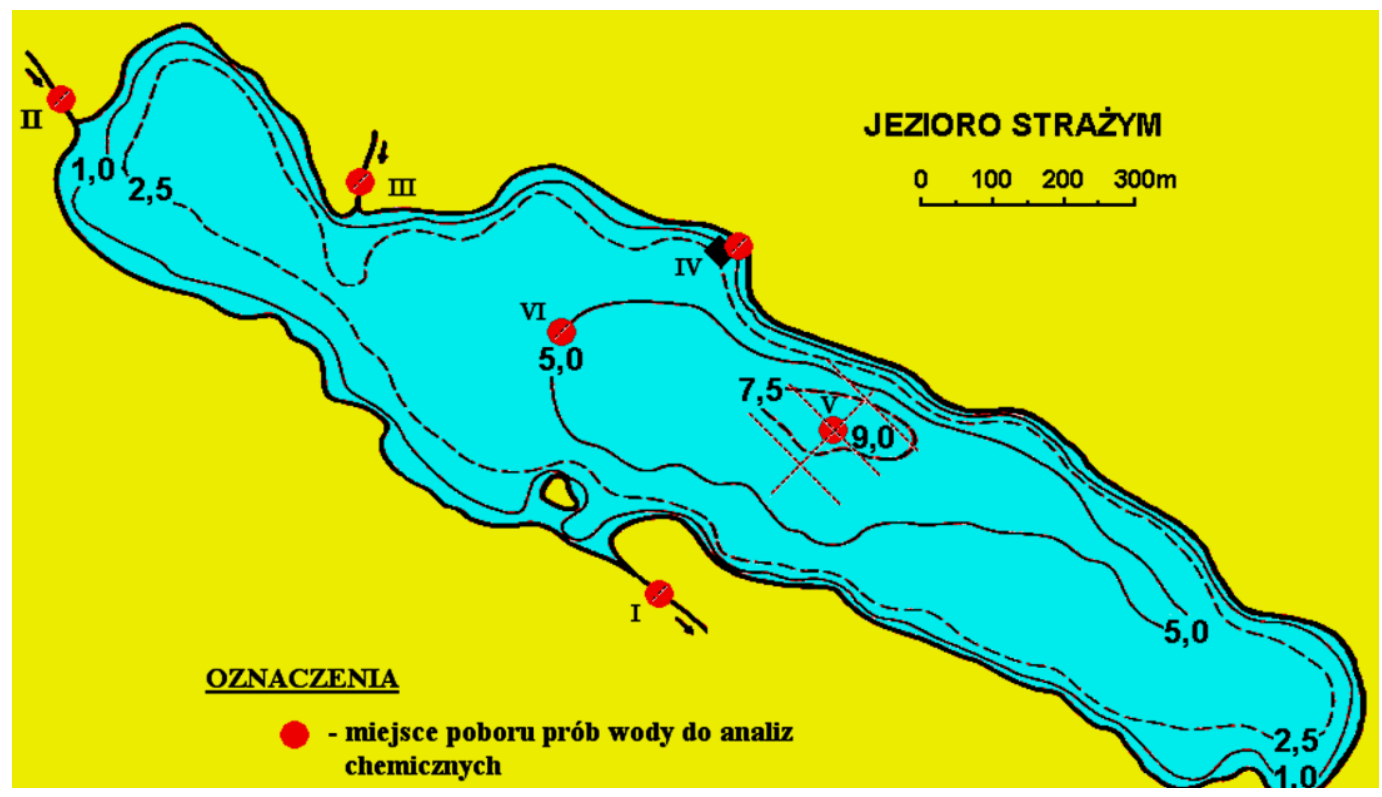

Schemat 1. Rozmieszczenie punktów badawczych na jeziorze Strażym, źródło: Polimat Toruń 
Ocenę jakości wód powierzchniowych jeziora Strażym prowadzono określając wartości 19 wskaźników, które określają jakość wód, a są uznawane za podstawowe [10-12] przy ustalaniu statusu ogólnego, trofii i mineralizacji wód.

Próby wody do badań pobierano według PN/C-04632.03 z głębokości ok. 0,5 m poniżej lustra wody. W miejscu poboru prób oznaczano temperaturę, $\mathrm{pH}$, potencjał redoks (Eh) oraz alkaliczność ogólną wód. Pobrane próbki wody zostały utrwalane zgodnie z zaleceniami zawartymi w Polskiej Normie - PN/C-04632.04.

Pozostałe wskaźniki określające jakość wód zostały oznaczone w przeciągu 24 godzin od momentu pobrania prób. Oznaczenie ilości rozpuszczonej materii organicznej podatnej na utlenienie określano jako ChZT-Mn zgodnie z PN/C-04578.02. Tlen rozpuszczony oznaczono metodą Winklera w modyfikacji azydkowej Alsterberga $\mathrm{z}$ zastosowaniem PN/C-04545.03.

W wyniku oznaczeń „suchej pozostałości” i „pozostałości po prażeniu” - według PN/C-04541, określono ilość substancji rozpuszczonych po wprowadzeniu poprawki na ubytek masy związanej z rozkładem wodorowęglanów oraz szacować ilość rozpuszczonej materii organicznej [17].

W niniejszej pracy spośród wskaźników trofii wód oznaczono również stężenie $\mathrm{NH}_{4}{ }^{+}$- zgodnie z PN/C-04576.01, $\mathrm{NO}_{2}^{-}$- zgodnie z PN/C-04576.06, $\mathrm{NO}_{3}^{-}$- zgodnie z PN/C04576.09, $\mathrm{PO}_{4}{ }^{3-}$ rozp - zgodnie z PN/C-04537.02 i $\mathrm{P}_{\mathrm{og}}$ - zgodnie z PN/C-04537.09.

Ocenę wskaźników mineralizacji badanego zbiornika wodnego tj. ogólne wskaźniki mineralizacji oraz makroskładniki i wybrane mikroskładniki mineralizacyjne: przewodnictwo elektrolityczne właściwe oznaczano zgodnie z PN/C-04542, twardość ogólną - oznaczano zgodnie z PN/C-04554.02, stężenie wapnia i magnezu - oznaczano zgodnie z PN/C-04551.01 i PN/C-04562.01, stężenie chlorków - oznaczano zgodnie z PN/C-04617.02, siarczanów (VI) - oznaczano zgodnie z PN/C-04566.09, alkaliczność ogólną - oznaczano zgodnie z PN/C04540.03, stężenie $\mathrm{Fe}_{\mathrm{og}}$ - oznaczano zgodnie z PN/C-04586.03 i $\mathrm{Mn}_{\mathrm{og}}$ - oznaczano zgodnie z PN/C-04590.01.

Poszczególne wskaźniki jakości wód oceniano według kryteriów zalecanych do oceniania śródlądowych wód powierzchniowych określonych w Rozporządzeniu Ministra Środowiska z dnia 11 lutego 2004 r. w sprawie klasyfikacji dla prezentowania stanu wód powierzchniowych i podziemnych, sposobu prowadzenia monitoringu oraz sposobu interpretacji wyników i prezentacji stanu tych wód.

W pracy przedstawiono 19 wskaźników określających jakość wód, wśród których 18 było zawartych w przytoczonym powyżej rozporządzeniu.

\section{DYSKUSJA WYNIKÓW I WNIOSKI}

Wyniki badań wybranych wskaźników wód jeziora Strażym wraz z klasyfikacją wartości zmierzonych wskaźników wg kryteriów zawartych w Rozporządzeniu Ministra Środowiska z dnia 11 lutego 2004 r. przedstawiono w tabeli 1. 
Tabela 2. Wyniki badań jakości wód powierzchniowych jeziora Strażym wraz z klasyfikacją wartości badanych wskaźników wg kryteriów Rozporządzenia Ministra Środowiska z dnia 11 lutego 2004 r.

\begin{tabular}{|c|c|c|c|c|}
\hline \multirow{2}{*}{$\begin{array}{l}\text { Lp. } \\
\text { No }\end{array}$} & \multirow{2}{*}{$\begin{array}{l}\text { Wskaźnik jakości wód (jednostki) } \\
\text { Water quality indices (units) }\end{array}$} & \multicolumn{3}{|c|}{$\begin{array}{l}\text { Jezioro Strażym } \\
\text { Strażym Lake }\end{array}$} \\
\hline & & 10.07.2009 & 12.08 .2009 & 15.09 .2009 \\
\hline 1 & 2 & 3 & 4 & 5 \\
\hline \multicolumn{5}{|c|}{ I. Parametry ogólne / General parameters } \\
\hline I.1 & Temperatura wody / Water temperature $\quad\left({ }^{\circ} \mathrm{C}\right)$ & $15,8(\mathrm{I})$ & $16,2(\mathrm{I})$ & $15,2(\mathrm{I})$ \\
\hline I. 2 & $\begin{array}{l}\text { (jedn. pH) } \\
\text { (pH units) }\end{array}$ & $7,62(\mathrm{I})$ & $7,72(\mathrm{I})$ & 7,70 (I) \\
\hline I.3 & ChZT-Mn / COD-Mn & 8,4 (III) & 8,9 (III) & 8,2 (III) \\
\hline I.4 & $\mathrm{BZT}_{5} / \mathrm{BOD}_{5}$ & 5,2 (III) & 5,5 (III) & 5,8 (III) \\
\hline I.5 & $\mathrm{O}_{2 \text { rozp. }} / \mathrm{O}_{2 \text { diss. }}$ & 8,9 (I) & $9,5(\mathrm{I})$ & $8,6(\mathrm{I})$ \\
\hline I.6 & Natlenienie wód ${ }^{1)} /$ Saturation with $\mathrm{O}_{2}{ }^{1)}$ & 68,7 & 79,4 & 63,8 \\
\hline \multicolumn{5}{|c|}{ II. Zasobność wód w substancje biogenne/ Biogenics substances content } \\
\hline II.1 & $\mathrm{NO}_{3}^{-} \quad\left(\mathrm{mgN} \cdot \mathrm{dm}^{-3}\right)$ & $0,22(\mathrm{I})$ & $0,25(\mathrm{I})$ & $0,24(\mathrm{I})$ \\
\hline II.2 & $\left(\mathrm{mgN} \cdot \mathrm{dm}^{-3}\right)$ & 0,032 (II) & 0,036 (II) & 0,036 (II) \\
\hline II.3 & $\left(\mathrm{mgN} \cdot \mathrm{dm}^{-3}\right)$ & 1,61 (III) & 1,47 (II) & $1,43(\mathrm{I})$ \\
\hline II.4 & $\mathrm{PO}_{4}^{3-}$ rozp. $/ \mathrm{PO}_{4}^{3-}$ diss. & $1,08(\mathrm{~V})$ & 0,77 (IV) & $1,10(\mathrm{~V})$ \\
\hline II.5 & $\left(\mathrm{mg} \mathrm{P} \cdot \mathrm{dm}^{-3}\right)$ & 0,41 (III) & 0,43 (III) & 0,49 (III) \\
\hline \multicolumn{5}{|c|}{ III. Wskaźniki mineralizacji/ Mineralization indices } \\
\hline III.1 & $\begin{array}{l}\text { Przewodnictwo elektryczne właściwe/ } \\
\text { Specyfic electroconductivity }\end{array}$ & 510 (II) & 680 (II) & 600 (II) \\
\hline III. 2 & $\left(\mathrm{mg} \mathrm{Ca} \cdot \mathrm{dm}^{-3}\right)$ & 57 (II) & 54 (II) & 55 (II) \\
\hline III.3 & $\left(\mathrm{mg} \mathrm{Mg}^{\prime} \mathrm{dm}^{-3}\right)$ & $13(\mathrm{I})$ & $12(\mathrm{I})$ & $10(\mathrm{I})$ \\
\hline III. 4 & $\left(\mathrm{mg} \mathrm{Cl} \cdot \mathrm{dm}^{-3}\right)$ & 25 (I) & 30 (I) & 22 (I) \\
\hline III.5 & $\left(\mathrm{mg} \mathrm{SO}_{4} \cdot \mathrm{dm}^{-3}\right)$ & $82(\mathrm{I})$ & $71(\mathrm{I})$ & 93 (I) \\
\hline III.6 & Zasadowość ogólna / Total alkalinity & 153 (II) & 149 (II) & 151 (II) \\
\hline III.7 & $\mathrm{Fe}_{\text {og. }} / \mathrm{Fe}_{\text {tot. }} \quad\left(\mathrm{mg} \mathrm{Fe} \mathrm{dm}^{-3}\right)$ & 0,19 (II) & 0,28 (II) & $0,21(\mathrm{II})$ \\
\hline III.8 & $\left(\mathrm{mg} \mathrm{Mndm}{ }^{-3}\right)$ & 0,07 (II) & 0,09 (II) & 0,07 (II) \\
\hline
\end{tabular}

Objaśnienia/ explanation:

1) Wskaźnik jakości wód nie klasyfikowany w Rozporządzeniu Ministra Środowiska $\mathrm{z}$ dnia 11 lutego $2004 \mathrm{r}$.

Wody jeziora Strażym w okresie prowadzonych badań posiadały wartości $\mathrm{pH}$ zbliżone do obojętnego tj. od 7,62 do 7,72 - zaliczane są do I klasa jakości wód.

Mierzone wartościami Eh wskazywały na to, iż mierzony potencjał redoks był kształtowany przez parę redoksową: $\mathrm{NO}_{3}{ }^{-} / \mathrm{NH}_{4}{ }^{+}[15]$.

Tak znaczne niedotlenienie wód w jeziorze Strażym, świadczy o znacznej intensywności procesów rozkładu materii organicznej w badanym zbiorniku. Za taką tezą przemawiają także stosunkowo niskie wartości pH wody - wskazując na przewagę procesów dysymilacyjnych nad asymilacyjnymi. W ekosystemach wodnych badanego jeziora znaczne wartości straty przy prażeniu oraz nieodpowiadające im wartości ChZT-Mn jak wynika z szacowań, jakie dokonano na podstawie oznaczeń „suchej pozostałości” i „pozostałości po prażeniu” wg [17] oraz na podstawie wyników oznaczeń ChZT-Mn, którego wartości zawsze odpowiadały III klasie jakości wód - badane wody jeziora cechowały się utrzymującą się we wszystkich porach roku dość znaczną zawartością substancji organicznych, w tym substancji o charakterze reduktorów. Przyczynę tego stanu należy upatrywać również w osadzie dennym badanego jeziora, który zasobny jest w materię organiczną. Badane wody jeziora Strażym zawierały zawsze stosunkowo mało mineralnych związków azotu - stężenia mineralnych form azotu odpowiadały zazwyczaj II klasie jakości wód. Badane wody posiadały 
zmieniające się stężenia $\mathrm{PO}_{4}{ }^{3-}$ rozp $\mathrm{i}_{\mathrm{og}}$ - stężenia te odpowiadały wodom od IV do V klasy jakości. Wzrost stężeń związków fosforu w badanym jeziorze może świadczyć o spadku ilości tlenu $\mathrm{w}$ wodach naddennych $\mathrm{i}$ zmianami ich statusu redoks prowadzącymi do uwalniania związków fosforu skumulowanych w osadach dennych [13].

Ekosystem jeziora Strażym jest zasobny w związki fosforu, które stanowią obciążenie wewnętrzne tego ekosystemu. Przemawia za tym uwalnianie z osadów do toni wodnej obok związków fosforu, także manganu i żelaza do wartości odpowiadających II klasie jakości wód.

Wartości $\mathrm{P}_{\mathrm{og}} \mathrm{W}$ okresie cyrkulacji wiosennej, kiedy to stężenie tego wskaźnika wynosiło około $0,41-0,49 \mathrm{mg} \mathrm{P} \cdot \mathrm{dm}^{-3}$ wskazuje na to, że wody badanego jeziora Strażym były w stanie zaawansowanej eutrofii [16]. Wskaźniki mineralizacji wód badanego jeziora cechowały się ustabilizowanym stężeniem badanych makroskładników jonowych wody.

\section{Polskie Normy}

PN/C-04537.02. Oznaczanie rozpuszczonych orto-fosforanów kolorymetryczną metodą molibdenianową z chlorkiem cynawym jako reduktorem.

PN/C-04537.09. Woda i ścieki. Badania zawartości związków fosforu. Oznaczenie fosforu ogólnego.

PN/C-04540.03. Badania wartości pH, kwasowości i zasadowości. Oznaczanie kwasowości i zasadowości mineralnej i ogólnej metodą miareczkowania wobec wskaźników.

PN/C-04541. Oznaczanie suchej pozostałości, pozostałości po prażeniu, straty przy prażeniu oraz substancji rozpuszczonych, substancji mineralnych i substancji rozpuszczonych lotnych.

PN/C-04542. Oznaczanie przewodności elektrolitycznej właściwej.

PN/C-04545.03. Oznaczanie rozpuszczonego tlenu metodą Winklera w modyfikacji azydkowej.

PN/C-04551.01. Oznaczanie wapnia (twardości wapniowej) metodą wersenianową.

PN/C-04554.02. Oznaczanie twardości ogólnej powyżej 0,357 mval/ $\mathrm{dm}^{3}$ metodą wersenianową.

PN/C-04562.01. Oznaczanie magnezu metodą wersenianową.

PN/C-04566.09. Badania zawartości siarki i jej związków. Oznaczanie siarczanów metodą wagową.

PN/C-04576.01. Badania zawartości związków azotu. Oznaczanie azotu w postaci amoniaku i jonów amonowych.

PN/C-04576.06. Oznaczanie azotu azotynowego metodą kalorymetryczną $\mathrm{z}$ kwasem sulfanilowym i 1-naftyloaminą.

PN/C-04576.09. Oznaczanie azotu azotanowego metodą kalorymetryczną z p-fluorofenolem.

PN/C-04578.02. Badania zapotrzebowania tlenu i zawartości węgla organicznego. Oznaczanie chemicznego zapotrzebowania tlenu (ChZT) metodą nadmanganianową.

PN/C-04586.03. Oznaczanie żelaza ogólnego i rozpuszczonego w zakresie $0,02-10 \mathrm{mg} / \mathrm{dm}^{3}$ metodą kolorymetryczną z 1,10-fenantroliną lub 2,2'-dwupirydylem.

PN/C-04590.01. Oznaczanie manganu metodą kolorymetryczną nadmanganianową. 
PN/C-04617.02. Oznaczanie chlorków w wodzie i ściekach metodą argentometrycznego miareczkowania.

PN/C-04632.03. Ogólne zasady pobierania próbek do badań fizycznych, chemicznych i biologicznych. Technika pobierania próbek.

PN/C-04632.04. Ogólne zasady pobierania próbek do badań fizycznych, chemicznych i biologicznych. Utrwalanie i przechowywanie próbek.

PN/C-06504. Przygotowanie roztworów buforowych.

\section{References}

[1] Barik S. K., Purushothaman C. S., Mohanty A. N., Aquacult. Res. 32 (2001) 819-832.

[2] Brodzińska B., Janczak J., Kowalik A., Sziwa R., Atlas jezior Polski. T. 1. Poznań 1996

[3] Brodzińska B., Janczak J., Kowalik A., Sziwa R., Atlas jezior Polski. T. 2. Poznań 1997

[4] Choiński Adam, Katalog jezior Polski, Wydawnictwo Naukowe UAM, Poznań 2006, s. 399.

[5] Daniszewski P., International Letters of Chemistry, Physics and Astronomy 1 (2012) 6-12.

[6] Daniszewski P., International Letters of Chemistry, Physics and Astronomy 1 (2012) 13-16.

[7] Daniszewski P., International Letters of Chemistry, Physics and Astronomy 2 (2012) 35-41

[8] Daniszewski P., International Letters of Chemistry, Physics and Astronomy 2 (2012) 42-45

[9] Daniszewski P., International Letters of Chemistry, Physics and Astronomy 2 (2012) 46-52

[10] Dojlido J. R., Chemia wód powierzchniowych, Wydawnictwo Ekonomia i Środowisko 1995

[11] Elbanowska H., Zerbe J., Siepak J.. Fizyczno-chemiczne badania wód. Wydawnictwo Naukowe PWN: 1999, s. 232

[12] Hermanowicz W., Dojlido J., Dożańska W., Koziorowski B., Zerbe J., Fizyczno-chemiczne badanie wody i ścieków, Arkady, Warszawa 1999

[13] Kajak Z., Hydrobiologia-Limnologia. Ekosystemy wód śródlądowych, PWN, Warszawa 1998, s. 355.

[14] Kentzer A., Fosfor i jego biologicznie dostepne frakcje w jeziorach o różnej trofii, Wydawnictwo UMK, Torun 2001, s. 111.

[15] Kölling M., Vergleich verschiedener Methoden zur Bestimmung des Redoxpotentials natürlicher Wässer. Meyniana. 38 (1986) 1-19.

[16] Lampert W., Sommer U.. Ekologia wód śródlądowych. Wyd. Nauk. PWN, Warszawa 2001, s. 415.

[17] Macioszczyk A., Hydrogeochemia. Wyd. Geologiczne, Warszawa 1987, s. 475. 
[18] Marcinkiewicz W., Barlineckie Jezioro, Wyd. Instytut Rybactwa Śródlądowego, Olsztyn 1963

[19] Rozporządzenie Ministra Środowiska z dnia 11 lutego 2004 r. w sprawie klasyfikacji dla prezentowania stanu wód powierzchniowych i podziemnych, sposobu prowadzenia monitoringu oraz sposobu interpretacji wyników i prezentacji stanu tych wód.

(Dz. U. Nr 32, poz. 284)

[20] Siuda W., Post. Mikrobiol. 40 (2), (2001) 187-217.

[21] Dąbrowska-Prot E., Hilbricht-Ilkowska A., Ochr. Sr, 15, (3-4), (1991) 237-250

[22] Kajak Z., Eutrofizacja jezior, Warszawa 1979

[23] Kalff J., Limnology, New Jersey 2001 